\title{
LOS REQUISITOS PROCESALES EN SERIO: LA EXISTENCIA DE UNA «CONTROVERSIA INTERNACIONAL»EN LA JURISPRUDENCIA DE LA CORTE INTERNACIONAL DE JUSTICIA
}

\author{
Asier GARRIDO MUÑOZ*
}

SUMARIO: 1 . INTRODUCCIÓN: EL FORMALISMO Y SUS CRÍTICOS.-2. LA CONTROVERSIA INTERNACIONAL, NOCIÓN SIEMPRE INACABADA.-2.1. Definición del término.-2.2. Flexibilidad: la existencia de una controversia como una cuestión de «sustancia» y no de forma.-2.2.1. Los sujetos de la controversia y las controversias multilaterales.-2.2.2. La formalización de la controversia.-2.2.3. El método para determinar la existencia de una controversia.-2.3. Formalismo: una tendencia in crescendo.-2.3.1. La necesidad de una "oposición positiva» de puntos de vista.-2.3.2. El «conocimiento» de la existencia de la controversia.-2.3.3. La limitada relevancia de los intercambios procesales entre las partes.-3. ¿FORMALISMO SIN CAUSA? CONTROVERSIA INTERNACIONAL Y FUNCIÓN JUDICIAL DE LA CORTE.-3.1. El criterio del «conocimiento»: tentativa de justificación.-3.1.1. No tan novedoso: el conocimiento en la jurisprudencia previa de la Corte.-3.1.2. No tan subjetivo: conocimiento y «estado mental» del Estado.-3.1.3. No tan formalista: la prueba del conocimiento.-3.2. El elemento temporal de la controversia internacional y la función judicial de la Corte: tentativa de explicación.-4. CONCLUSIONES.

\section{INTRODUCCIÓN: EL FORMALISMO Y SUS CRÍTICOS}

1. Las recientes sentencias de la Corte Internacional de Justicia (CIJ o «la Corte» $)^{1}$ en los tres casos sobre las Obligaciones relativas a las negociaciones sobre el cese de la carrera de armas nucleares y el desarme nuclear («sentencias relativas a las obligaciones nucleares») constituyen la primera ocasión en que el Alto Tribunal desestima por completo una demanda debido a la inexisten-

* Letrado de la Corte Internacional de Justicia (A.Garrido@icj-cij.org). Las opiniones expresadas en el presente estudio son realizadas a título exclusivamente personal del autor y no comprometen en modo algo a la institución para la que trabaja. El contenido no revela información confidencial alguna ni debe entenderse en el sentido de revelar dicha información. Todas las páginas web de referencia han sido consultadas por última vez el 10 de octubre de 2017.

1 El autor utilizará en el presente estudio el término «Corte» (utilizado en la versión española de la Carta de las Naciones Unidas) sin pretender entrar en debates sobre si es más adecuado que «Tribunal». 
cia de una controversia internacional ${ }^{2}$. Previamente, la Corte había declinado en dos ocasiones conocer ciertos aspectos de algunas demandas por similares motivos, pero nunca con consecuencias tan decisivas ${ }^{3}$.

2. Las sentencias han sido recibidas con críticas por la doctrina, que de manera mayoritaria ha contestado la forma y el fondo de la decisión siguiendo la trayectoria de las opiniones disidentes que acompañan el texto principal $^{4}$. En particular, se ha criticado la «creación» de un «nuevo» requisito para determinar la existencia de una controversia (el «conocimiento» de la existencia de la controversia por el demandante en el momento de plantearse la demanda), así como la aplicación de este al caso de autos ${ }^{5}$. Se ha argumentado igualmente que la decisión de la Corte buscaba proteger a los demandados (que en su origen eran todos los Estados nucleares y que, debido a la manifiesta falta de competencia respecto de algunos de ellos, se redujeron al Reino Unido, India y Pakistán) de un eventual fallo contrario a sus intereses ${ }^{6}$. Y siguiendo este hilo argumental, se han cuestionado las implicaciones de las tres sentencias para el papel de la Corte en el arreglo pacífico de controversias y en la garantía del cumplimiento con el Derecho internacional ${ }^{7}$. Existe

2 Obligaciones respecto de las negociaciones sobre la cesación de la carrera de armamentos nucleares y el desarme nuclear (Islas Marshall c. India; Islas Marshall c. Pakistán; Islas Marshall c. Reino Unido), Sentencias de 5 de octubre de 2016, no publicadas todavía. Por razones de conveniencia, en este trabajo se citará cuando sea posible solo la primera de las sentencias.

3 Asunto sobre las supuestas violaciones de derechos soberanos y espacios marítimos (Nicaragua c. Colombia), Sentencia de 17 de marzo de 2016, ICJ Reports 2016, p. 33, párrs. 75-78; Cuestiones relativas a la obligación de juzgar o extraditar (Bélgica c. Senegal), Sentencia de 20 de julio de 2012, ICJ Reports 2012, pp. 444-445, párr. 54. Véase también Compañía de Electricidad de Sofía y Bulgaria (Bélgica c. Bulgaria), Sentencia de 4 de abril de 1939, PCIJ, Series A/B, núm. 77, p. 83.

4 Véanse Becker, M., "The Dispute that Wasn't there: Judgments in the Nuclear Disarmament Cases at the International Court of Justice», Cambridge International Law Journal, vol. 6, 2017, núm. 1, pp. 4-26; KRISH, N., "Capitulation in The Hague: The Marshall Islands Cases», EJIL Talk!, https://www. ejiltalk.org/capitulation-in-the-hague-the-marshall-islands-cases/; PALESTINI, L., "Forget About Mavrommatis and Judicial Economy: The Alleged Absence of a Dispute in the Cases Concerning the Obligations to Negotiate the Cessation of the Nuclear Arms Race and Nuclear Disarmament», JIDS, vol. 8, 2017, núm. 3, pp. 557-577; ProulX, V.-J., «The World's Court's Jurisdictional Formalism and its Lost Market Share: The Marshall Islands Decisions and the Quest for a Suitable Dispute Settlement Forum for Multilateral Disputes», LJIL, 2017 (disponible en vista preliminar), así como las contribuciones de Antony T. Anghie, Ingo Venzke, George R. B. Galindo, Andrea Bianchi, Surabhi Ranganathan y VicentJ. Prouxl al simposio de AJIL Unbound «The Marshall Islands Cases» publicado en vol. 111, 2017, disponible en https://www.cambridge.org/core/journals/american-journal-of-international-law/. Para un análisis menos crítico, véase KolB, R., "Chronique de la jurisprudence de la Cour internationale de Justice en 2016», RSDIUE, vol. 27, 2017, núm. 1, pp. 69-101.

5 Véase, en particular, BIANCHI, A., "Choice and (the awareness of) its Consequences: the ICJ's "Structural Bias" Strikes again in the Marshall Islands case», loc. cit., nota 4, p. 83, y las opiniones disidentes o particulares de los siguientes Jueces: Yusuf (párrs. 10-12); Bennouna (no incluye párrafos); Cançado Trindade (párrs. 19-21); Sebutinde (párrs. 30-33); Robinson (párrs. 23-40), y Crawford (párrs. 4-6); así como del Juez ad hoc Bedjaoui (párrs. 25-33) (más detalles en infra, nota 53).

${ }^{6}$ BianchI, A., loc. cit., nota 5, pp. 82-87, y KRISCH, N., loc. cit., nota 4. Véase el art. 38.5 del Reglamento de la Corte, según el cual «[c]uando el demandante pretenda fundar la competencia de la Corte en un consentimiento todavía no dado o manifestado por el Estado contra quien se haga la solicitud, esta última se transmitirá a ese Estado. No será, sin embargo, inscrita en el Registro General ni se efectuará ningún acto de procedimiento hasta tanto el Estado contra quien se haga la solicitud no haya aceptado la competencia de la Corte a los efectos del asunto de que se trate».

7 Véase, en particular, BIANCHI, A., loc. cit., nota 5, pp. 86-87. 
común acuerdo, eso sí, en que aun si la Corte hubiera considerado satisfecho el criterio de la existencia de una controversia, el demandante todavía habría tenido que superar las otras objeciones preliminares planteadas por los demandados ${ }^{8}$.

3. En fin, dichas críticas pueden resumirse en la identificación de un creciente "formalismo» de la Corte. Formalismo entendido por ciertos autores no solo como priorización de la forma (aquí los requisitos procesales) sobre el fondo (la resolución de la controversia concreta), sino también como triunfo de la técnica jurídica sobre la realización de la justicia material. En el caso concreto de la negociación del desarme nuclear, ello impidió el ejercicio por la Corte de su competencia en una materia que previamente había definido como «de vital importancia para el conjunto de la comunidad internacional» ${ }^{9}$.

4. Una valoración de ciertos detalles de las tres sentencias sugiere la existencia de interrogantes sobre el requisito de la existencia de una controversia que van más allá de la cuestión concreta del desarme nuclear, cuya resolución puede arrojar luz sobre el fundamento de esta tendencia «formalista» de la Corte. Las sentencias fueron adoptadas por una estrecha mayoría, que en el caso del Reino Unido requirió el voto preponderante del Presidente - uno de los jueces votó con la mayoría solo respecto de las demandas concernientes a India y Pakistán-. Además, varios de los jueces disidentes en los tres asuntos habían votado a favor de la sentencia sobre objeciones preliminares dictada en el Asunto sobre las supuestas violaciones de derechos soberanos y espacios marítimos. En dicha sentencia, la Corte había considerado que, en el momento de plantearse la demanda, Nicaragua no había probado que tuviera una controversia con Colombia relativa al uso de la fuerza en ciertos espacios marítimos ${ }^{10}$.

8 A este respecto, véanse en particular las opiniones particulares del Juez Tomka (párrs. 31-41, relativa a la capacidad de la Corte de resolver controversias relativas a obligaciones que requieren la cooperación de Estados no parte en la controversia) y del Juez Crawford (párrs. 29-30, relativa a la aplicabilidad al caso de la doctrina del Oro Amonedado).

9 Legalidad de la amenaza o el empleo de las armas nucleares, Dictamen consultivo de 8 de julio de 1996, p. 265, párr. 103. Véase, por todas, la Opinión disidente del Juez Bennouna (sin párrafos): «Dans la relation du droit international au temps, il y a la part du rationnel [...] et la part du pragmatisme, afin de tenir compte des caractéristiques de telle ou telle situation. L'art du juge est de parvenir au bon dosage afin que justice soit faite et qu'elle soit perçue comme telle». Y también KRISCH, N., loc. cit., nota 4 y VENZKE, I., loc. cit., nota 4, pp. 72-74.

${ }^{10}$ Igualmente, dos de los jueces ahora en la mayoría (el Presidente Abraham y la Jueza Donoghue) se habían mostrado contrarios a la línea jurisprudencial ahora seguida en las sentencias relativas a las obligaciones nucleares [véanse sus opiniones en los asuntos sobre la Aplicación de la Convención Internacional para la Eliminación de Todas las Formas de Discriminación Racial (Georgia c. Rusia), Sentencia de 1 de abril de 2011, ICJ Reports 2011, y Cuestiones relativas a la obligación de juzgar o extraditar (Bélgica c. Senegal), supra, nota 3]. El Juez Owada también había manifestado ciertas discrepancias respecto de la primera sentencia. En relación con el sentido del voto del Presidente Abraham, se apuntará que ha seguido el camino contrario al del Presidente Spender en el Asunto del Sudoeste Africano. Mientras que este último se valió en 1966 de su voto preponderante para favorecer una sentencia contraria a la dictada previamente por la Corte en 1962, respecto de la cual había disentido; el primero ha utilizado su voto preponderante para posibilitar una sentencia que sigue lo que él considera la línea jurisprudencial más reciente de la Corte, respecto de la cual había disentido en su momento. Lo hace, 
5. Ello nos lleva a cuestionarnos si existe una línea jurisprudencial clara sobre el mencionado requisito. Y si no es el caso, si el «formalismo» mostrado en los asuntos más recientes es fruto únicamente de las circunstancias de los casos de autos, o si por el contrario existe una lógica que pueda fundamentar el tenor de esta jurisprudencia. Ambos interrogantes solo pueden ser respondidos poniendo las cosas en la perspectiva de la jurisprudencia de la Corte y su predecesora, a fin de determinar el origen y evolución de la noción de "controversia internacional» y su posible conexión con la función judicial de aquella.

6. Este trabajo se propone dicho objetivo. Para ello, se explicará en primer lugar que la noción de controversia ha sido tradicionalmente interpretada con cierta flexibilidad, y que es en una serie de sentencias (la mayoría recientes) cuando, de manera progresiva y en respuesta a las particulares circunstancias de cada caso, se ha ido definiendo el contenido mínimo de la noción.

En segundo lugar, se evaluarán los «nuevos» requisitos mínimos de la noción de controversia internacional: el criterio del conocimiento y la necesidad de que la controversia surja antes de la demanda. Respecto del primero, se explicará que no es ni tan novedoso, ni tan subjetivo ni tan formalista como se ha sugerido. En relación con el segundo (pieza clave de las sentencias relativas a las obligaciones nucleares) se intentará explicar su conexión con la protección de la función judicial de la Corte cuando se plantean demandas unilaterales. El análisis de estas cuestiones nos llevará a concluir que existe una lógica jurídica en el razonamiento de la Corte, lógica que ha justificado la opción de «tomarse en serio» un importante requisito procesal sobre el que a menudo se había pasado de puntillas.

\section{LA CONTROVERSIA INTERNACIONAL, NOCIÓN SIEMPRE INACABADA}

\subsection{Definición del término}

7. El art. 38.1 del actual Estatuto de la Corte define la función de esta como «decidir conforme al derecho internacional las controversias que le sean sometidas», lo que sugiere que la existencia de una "controversia internacional» es un requisito que afecta al núcleo de su función jurisdiccional ${ }^{11}$.

según explica en su Declaración, por razones de respeto a la «continuidad» en la jurisprudencia de la CIJ (Declaración del Presidente Abraham, párr. 10). Véase el Asunto del Sudoeste Africano (Etiopía c. Sudáfrica y Liberia c. Sudáfrica), Sentencias de 18 de julio de 1966, ICJ Reports 1966 y Sentencias sobre objeciones preliminares de 21 de diciembre de 1962, ICJ Reports 1962 (opinión disidente conjunta de los Jueces Spender y Fitzmaurice).

11 Aparte de esta disposición, el término "controversia» aparece mencionado igualmente en los arts. 36.2, 40.1 y 60 del Estatuto. Destaca el primero de ellos, según el cual «[1]os Estados partes en el presente Estatuto podrán declarar en cualquier momento que reconocen como obligatoria ipso facto y sin convenio especial, respecto a cualquier otro Estado que acepte la misma obligación, la jurisdicción de la Corte en todas las controversias de orden jurídico que versen sobre [...]» (cursiva añadida). 
Sin embargo, no se aporta ningún elemento adicional que permita comprender el alcance del término.

Ello es reflejo de las discusiones mantenidas por el Comité de Juristas encargado de preparar un proyecto de Estatuto de la CPJI (origen del actual Estatuto), cuyo informe final solo indicaba que la Corte sería «competent to hear and determine cases at the request of states between whom a dispute exists [...] it is obvious that such a dispute can only be of an international nature» ${ }^{12}$. No hubo conclusiones claras al respecto, a pesar de que los debates del Comité abordaron problemas tales como la naturaleza de la controversia (legal, política o económica) y el papel de las negociaciones diplomáticas previas ${ }^{13}$. Además, de las transcripciones de las reuniones se desprende que los juristas que compusieron el Comité atribuían a las negociaciones previas un papel relevante en la definición de la controversia, si bien se trataba de una consideración fáctica y no tanto de la constatación de un criterio jurídico ${ }^{14}$.

8. En estas circunstancias, fue la propia CPJI quien, en su sentencia de 1923 en el Asunto de las concesiones Mavrommatis en Palestina, definió «controversia internacional» como «un desacuerdo sobre una cuestión de derecho o de hecho, un conflicto de opiniones jurídicas o de intereses entre dos personas» ${ }^{15}$. La definición era imprecisa respecto de ciertas cuestiones que interesan en tiempos actuales, entre las cuales, a efectos del presente trabajo, destacan las relativas al tiempo y la forma ${ }^{16}$. Y es que se dejaban abiertos los problemas del momento en que se tenía que producir el «conflicto de opiniones jurídicas» (antes o después de la demanda) y la modalidad de formalización de este (si era necesaria una notificación formal, quizá seguida de negociaciones previas, o si bastaba con constatar la existencia fáctica de posiciones divergentes entre los Estados parte). Al mismo tiempo, esta definición presentaba la ventaja de su apertura y flexibilidad. Téngase en cuenta que dicha definición no buscaba tanto determinar el contenido de la competencia de la Corte, sino más bien articular una definición general que pudiera tener

12 Procès-Verbaux des séances du Comité avec annexes (16 juin-24 juillet 1920), La Haya, Van Langenhuysen Frères, 1920, p. 730.

13 La cuestión de las competencia de la Corte respecto de las controversias políticas no se abordará en el presente trabajo.

${ }_{14}$ Durante la 12. ${ }^{\text {a }}$ sesión de los debates que tuvieron lugar en el Palacio de la Paz, el presidente llegó a afirmar que "diplomatic means, in the ordinary sense of these words, should be exhausted before the appeal to the tribunal» [Procès-Verbaux des séances du Comité avec annexes (16 juin-24 juillet 1920), op. cit., nota 12, p. 260]. Lo hizo en relación a un proyecto de art. 3 del Estatuto que requería dichas negociaciones previas. Algunos ponentes recalcaron a este respecto que dicho requisito figuraba en numerosos tratados internacionales (ibid., p. 263). Como es sabido, finalmente el proyecto de art. 3 desapareció de la versión final del Estatuto (más detalles en ibid., pp. 254 y 260-263).

${ }_{15}$ Asunto de las concesiones Mavrommatis en Palestina (Grecia c. Reino Unido), Sentencia de 30 de agosto de 1924, PCIJ, Series A, núm. 2, p. 11.

16 Sobre el carácter amplio de la definición, véase DE VISSCHER, Ch., «Les avis consultatifs de la Cour permanente de Justice internationale», RCADI, vol. 1, 1929, pp. 23-24 y 57. Para un análisis de la decisión de la Corte respecto de su competencia, véanse entre otros DE VINEUIL, P., «Les décisions de la cinquième session ordinaire de la Cour Permanente de Justice Internationale», Revue de droit international et de législation comparée, 1925, pp. 98-114, y Hudson, M. O., The Permanent Court of International Justice 1920-1942. A Treatise, Nueva York/Londres, Garland Publishing, 1972, pp. 414-415. 
valor consuetudinario, y que como tal fuera aplicable a todo tipo de cláusulas jurisdiccionales presentes en tratados internacionales ${ }^{17}$.

9. A partir de aquí, tanto la CPJI como la CIJ (esta última en mayor medida) han ido perfilando la noción. Dichas precisiones se han ido formulando de manera casuística, pues como se explicará más adelante la CIJ no siempre ha aplicado una metodología clara al análisis de esta cuestión. Además, no siempre es posible determinar con exactitud si las indicaciones de la Corte se refieren a la noción general de "controversia» o a las versiones más restrictivas de la misma que figuran en cláusulas jurisdiccionales convencionales.

10. Sea como fuere, si hay que identificar dos polos entre los cuales se puede situar la jurisprudencia, estos son los de la flexibilidad y el rigor. Es en torno a ambos que se articulará el análisis llevado a cabo en esta sección.

\subsection{Flexibilidad: la existencia de una controversia como una cuestión de "sustancia» y no de forma}

11. La Corte ha reiterado en numerosas ocasiones que la existencia de una controversia es una cuestión de «sustancia» que no depende de la forma en que se presente. Esta afirmación se ha sustentado en una serie de precisiones en torno a los sujetos y el contexto formal de la controversia.

\subsubsection{Los sujetos de la controversia y las controversias multilaterales}

12. El primer gran debate generado en torno a la noción se planteó en el Asunto del Sudoeste Africano respecto del número de sujetos de la controversia. Ciertamente, no fue la primera vez que se discutió la competencia de la Corte para conocer en vía contenciosa de una controversia que afectaba a más de dos Estados ${ }^{18}$. Pero sí fue novedoso que los demandantes invocaran ante una jurisdicción esencialmente bilateral la violación de una obligación erga omnes como la protección de la población de un territorio sometido a mandato de la Sociedad de las Naciones (SN), que no les había producido un perjuicio material directo.

13. Como es sabido, la Corte terminó concluyendo en 1966 que los demandantes no tenían legitimación activa debido a su falta de interés material para actuar. Pero en su sentencia de 1962 relativa a la competencia realizó

17 Kolb, R., The International Court of Justice, Oxford/Portland, Hart Publishing, 2013, p. 310. Como tal, la definición ha sido reiterada en alguna sentencia arbitral, como por ejemplo en la controversia relativa al Atún rojo del Sur (Nueva Zelanda-Japón, Australia-Japón), Sentencia de 4 de agosto de 2000, RIAA, vol. XXIII, p. 18.

18 Véase, en particular, el Asunto S. S. «Wimbledon», Sentencia de 17 de agosto de 1923, PCIJ, Series A, núm. 1, relativa a una demanda planteada por el Reino Unido, Francia, Italia (Polonia interviniente) contra el Imperio Alemán. Más conocida es la sentencia dictada en el Asunto del Oro amonedado sacado de Roma en 1943 (Italia c. Francia, Reino Unido y Estados Unidos), Sentencia de 15 de junio de 1954, ICJ Reports 1954, p. 34. 
una serie de precisiones de largo alcance respecto de las controversias multilaterales. En particular, en relación con la condición de entablar negociaciones previas antes de acudir a la Corte (art. 7 del Mandato de la SN de 1920 para el Sudoeste Africano), fue necesario determinar el contenido y circunstancias de las negociaciones entre las partes cuando estas tienen lugar en el seno de órganos de las Naciones Unidas. La Corte afirmó:

«diplomacy by conference or parliamentary diplomacy has come to be recognized in the past four or five decades as one of the established modes of international negotiation. In cases where the disputed questions are of common interest to a group of States on one side or the other in an organized body, parliamentary or conference diplomacy has often been found to be the most practical form of negotiation. The number of parties to one side or the other of a dispute is of no importance; it depends upon the nature of the question at issue. If it is one of mutual interest to many States, whether in an organized body or not, there is no reason why each of them should go through the formality and pretence of direct negotiation with the common adversary State after they have already fully participated in the collective negotiations with the same State in opposition» ${ }^{19}$.

14. Si bien estas afirmaciones se formularon en relación con una cláusula jurisdiccional concreta, es posible extenderlas a la definición general de controversia internacional ${ }^{20}$.

\subsubsection{La formalización de la controversia}

15. La jurisprudencia al respecto es constante e inequívoca: no hay un solo método para formalizar una controversia entre las partes. Esta regla se encuentra íntimamente relacionada con la relativa a la definición de controversia como una cuestión de «sustancia» y no de forma.

16. Cierto es, como se apuntó anteriormente, que en los años de la CPJI las negociaciones previas tuvieron mayor relevancia ${ }^{21}$. Ello explica que en la sentencia de 1924 dictada en el Asunto de las concesiones Mavrommatis en Palestina se afirmara que "before a dispute can be made the subject of an action at law, its subject matter should have been clearly defined by means of diplomatic negotiations». Lo mismo se aplica a la sentencia sobre la Interpretación de las sentencias núms. 7 y 8 (Fábrica de Chorzów), donde la Corte indicó lo siguiente:

«it would no doubt be desirable that a State should not proceed to take as serious a step as summoning another State to appear before the Court without having previously, within reasonable limits, endeavoured to make it quite clear that a difference of views is in question which has not been capable of being otherwise overcome» ${ }^{22}$.

19 Asunto del Sudoeste Africano (Etiopía c. Sudáfrica y Liberia c. Sudáfrica), supra, nota 10, p. 346.

20 Opinión disidente del Juez Crawford, supra, nota 2, párr. 20.

${ }^{21}$ Couvreur, Ph., The International Court of Justice and the Effectiveness of International Law, Leiden/Boston, Brill, 2017, pp. 100-101.

22 Interpretación de las sentencias núms. 7 y 8 (Fábrica de Chorzów) (Alemania c. Polonia), Sentencia de 16 de diciembre de 1927, PCIJ, Series A, núm. 13, pp. 11-12. 
17. Sin embargo, ninguna de las dos decisiones tiene trascendencia más allá de las circunstancias de cada caso. De hecho, en la segunda de las sentencias mencionadas (relativa a una demanda de interpretación de una sentencia previa de la Corte) se apuntó que:

"in the wording of the article [se refiere al artículo del Estatuto de la CPJI relativo a las demandas de interpretación, que requería un "desacuerdo" sobre la interpretación de una sentencia] the Court considers that it cannot require that the dispute should have manifested itself in a formal way; according to the Court's view, it should be sufficient if the two Governments have in fact shown themselves as holding opposite views in regard to the meaning or scope of a judgment of the Court» ${ }^{23}$.

18. Igualmente flexible fue la CPJI en el Asunto concerniente a ciertos intereses alemanes en la Alta Silesia polaca. En el contexto de una cláusula jurisdiccional que exigía a las partes negociaciones previas ${ }^{24}$, se aceptó la posibilidad de presentar una demanda unilateral tan pronto como una de ellas considerara que existe una divergencia de opiniones. Para ello, bastaba con que una de las partes "points out that the attitude adopted by the other conflicts with its own views» ${ }^{25}$.

19. Décadas más tarde, la CIJ siguió esta tendencia en su sentencia sobre objeciones preliminares en el Asunto de la frontera terrestre y marítima entre Camerún y Nigeria, precisando que no son necesarias las negociaciones previas entre las partes cuando una de ellas fundamenta la competencia en la cláusula facultativa del art. 36.2 del Estatuto ${ }^{26}$. Además, rechazó la necesidad de notificación previa por parte del demandante como condición previa a la presentación de la demanda. Lo hizo en relación con un «ataque sorpresa» de Camerún durante unas negociaciones fronterizas con Nigeria, cuando aceptó sin previo aviso la competencia obligatoria de la Corte ${ }^{27}$.

20. Por último, en una sentencia reciente, la Corte ha reiterado que, aunque una protesta formal «may be an important step to bring a claim of one party to the attention of the other», dicha protesta no es una precondición para la existencia de una controversia ${ }^{28}$. Esta afirmación se ha planteado en relación con supuestas violaciones por parte de Colombia de una delimitación marítima previamente efectuada por la Corte. Nicaragua no presentó protesta formal alguna contra Colombia hasta diez meses después de la demanda.

23 Ibid., p. 11. Sobre la definición de «desacuerdo» en el art. 60 del actual Estatuto, véase QuiNTANA Aranguren, J. J., Litigation at the International Court of Justice, Leiden/Boston, Brill, 2012, pp. 58-59.

24 Se trataba del art. 23 de la Convención Germano-Polaca relativa a la Alta Silesia de 1922, cuyo párr. 1 afirmaba que "[s]hould differences of opinion respecting the construction and application of Articles 6 to 22 arise between the German and Polish Governments, they shall be submitted to the Permanent Court of International Justice».

25 Asunto de los intereses alemanes en la Alta Silesia polaca (Alemania c. Polonia), Sentencia de 25 de agosto de 1925, PCIJ, Series A, núm. 6, p. 14.

${ }^{26}$ Asunto de la frontera terrestre y marítima entre Camerún y Nigeria (Camerún c. Nigeria), Sentencia sobre objeciones preliminares de 11 de junio de 1998, ICJ Reports 1998, p. 322, párr. 109.

27 Ibid., p. 297, párr. 39.

28 Asunto sobre las supuestas violaciones de derechos soberanos y espacios marítimos (Nicaragua c. Colombia), supra, nota 3, p. 32, párr. 72 . 
21. En suma, no son pocos los elementos que apuntan a una actitud flexible de la Corte respecto de la formalización de controversias internacionales. Como se expondrá más adelante, dicha actitud sigue en mi opinión en pie a pesar de los desarrollos que han tenido lugar en las tres sentencias relativas a las obligaciones nucleares.

\subsubsection{El método para determinar la existencia de una controversia}

22. Similares afirmaciones se pueden realizar respecto de la metodología utilizada por la Corte para determinar la existencia de una controversia. En efecto, la Corte ha establecido que la determinación "objetiva» de la existencia de una controversia requiere un examen de los hechos ${ }^{29}$; se trata del reverso de su competencia para determinar la materia de la controversia $^{30}$.

23. Los medios de prueba no difieren sustancialmente en las controversias bilaterales y en las multilaterales. En relación con las primeras, la Corte se apoya en declaraciones públicas, notificaciones y otros intercambios ${ }^{31}$. Así lo hizo en Bélgica c. Senegal para concluir sin dificultad que existía una controversia entre las partes relativa a la interpretación y aplicación de la Convención contra la Tortura ${ }^{32}$. Además, en Georgia c. Rusia la Corte se refirió al «autor», al «destinatario» $\mathrm{y}$ al «contenido» de los intercambios como aspectos relevantes para determinar que, en el caso concreto, existía una controversia relativa a la interpretación y aplicación de la Convención Internacional sobre la Eliminación de Todas las Formas de Discriminación Racial ${ }^{33}$. Si bien lo hizo en relación con una cláusula jurisdiccional que requería previo agotamiento de la vía diplomática y conexión con la citada Convención, en las sentencias relativas a las obligaciones nucleares la Corte ha extendido esta metodología a las cláusulas facultativas. En mi opinión, la relación de elementos no es exhaustiva, pues nada impide prestar atención, en particular, al contexto de las relaciones entre las partes.

24. En lo que respecta a las controversias multilaterales, no hay variaciones significativas, pues los intercambios en foros internacionales pueden ser igualmente relevantes. Ello ha sido confirmado en las sentencias relativas a

29 Ibid., p. 26, párr. 50; Interpretación de los Tratados de Paz concluidos entre Bulgaria, Hungría y Rumanía, Dictamen consultivo de 30 de marzo de 1950 (primera fase), ICJ Reports 1950, p. 74.

30 Sobre dicha competencia, véase por todas Obligación de negociar un acceso al Océano Pacífico (Bolivia c. Chile), Sentencia sobre objeciones preliminares de 24 de septiembre de 2015, ICJ Reports 2015, p. 602, párr. 26.

31 Sobre estas últimas, véase Torres Bernárdez, S., "Are Prior Negotiations a General Condition for Judicial Settlement by the International Court of Justice?», en BAREA, C. et al. (eds.), Liber Amicorum «In Memoriam» of José María Ruda, La Haya, Kluwer Law, 2000, p. 508.

32 Cuestiones relativas a la obligación de juzgar o extraditar (Bélgica c. Senegal), supra, nota 3, p. 444, párr. 52.

${ }^{3}$ Aplicación de la Convención Internacional para la Eliminación de Todas las Formas de Discriminación Racial (Georgia c. Rusia), Sentencia de 1 de abril de 2011, ICJ Reports 2011, p. 63, párr. 100 y p. 120 , párr. 113 . 
las obligaciones nucleares, en las que la Corte ha analizado dos declaraciones formuladas por las Islas Marshall en foros multilaterales - si bien concluyendo que, dados sus términos, ninguna de ellas podía justificar la existencia de una controversia en el caso concreto-. Para ello citó Georgia c. Rusia, otro precedente en el que se analizaron intercambios mantenidos en órganos de Naciones Unidas ${ }^{34}$.

25. Pero ahí no termina el antiformalismo de la Corte. Ante la eventualidad de que un demandado ignore la reclamación de un demandante, o incluso de que las partes no hayan mantenido contacto relevante alguno, la CIJ ha admitido la determinación de la existencia de una controversia por inferencia, es decir, en base al comportamiento de las partes.

Es lo que sucedió durante el procedimiento escrito y oral en el Asunto de la frontera terrestre y marítima entre Camerún y Nigeria, donde el demandado evitó precisar sus pretensiones respecto de los 1.600 kilómetros de frontera entre ambos países, más allá de ciertas territorios fronterizos respecto de las cuales el desacuerdo entre ambas partes era manifiesto ${ }^{35}$. Curiosamente, la Corte no fundamentó su conclusión en ciertos incidentes fronterizos invocados por el demandante, sino en la combinación del silencio total del demandado hacia dicha cuestión y su crítica de los tratados invocados por Camerún para justificar sus pretensiones territoriales ${ }^{36}$.

26. La norma sobre la inferencia de la controversia ha sido recientemente aplicada en el Asunto sobre las supuestas violaciones de derechos soberanos y espacios marítimos y en las tres sentencias relativas a las obligaciones $\mathrm{nu}$ cleares, con resultados ambivalentes. En la primera (que concierne a un asunto todavía pendiente) la Corte estimó que, en el momento de presentarse la demanda, Colombia «tenía conocimiento» de que Nicaragua consideraba que sus acciones constituían una violación de la frontera marítima delimitada en 2012 por la Corte (debido, en particular, a la promulgación de un decreto relativo al territorio litigioso y ciertas acciones de patrullaje del mismo) ${ }^{37}$. En las segundas, la Corte no necesitó referirse a la conducta de los demandados respecto de la negociación del desarme nuclear, pues en todo caso entendió que las Islas Marshall en ningún momento habían objetado dicha conducta con suficiente claridad ${ }^{38}$.

${ }^{34}$ Obligaciones respecto de las negociaciones sobre la cesación de la carrera de armamentos nucleares y el desarme nuclear (Islas Marshall c. India), supra, nota 2, párr. 46.

35 Se trataba en particular de Darak y las islas adyacentes, así como la península de Bakassi.

${ }^{36}$ Asunto de la frontera terrestre y marítima entre Camerún y Nigeria (Camerún c. Nigeria), supra, nota 26, pp. 313-317, párrs. 84-93. Se trataba, en todo caso, de uno de esos supuestos donde no es posible determinar con claridad si el problema de fondo era la existencia de una controversia o el contenido de la misma.

37 También se habían emitido declaraciones por parte de representantes nicaragüenses en relación con el cumplimiento por parte de Colombia con la sentencia de 2012 de la CIJ: véase Asunto sobre las supuestas violaciones de derechos soberanos y espacios maritimos (Nicaragua c. Colombia), supra, nota 3, pp. 31-33, párrs. 67-73.

38 Obligaciones respecto de las negociaciones sobre la cesación de la carrera de armamentos nucleares y el desarme nuclear (Islas Marshall c. India), supra, nota 2, párr. 52. 


\subsection{Formalismo: una tendencia in crescendo}

27. Como contrapunto de esta línea jurisprudencial, sentencias recientes apuntan a la existencia de límites a la actitud flexible recién comentada, evidenciando un cierto formalismo judicial — término que en esta sección debe entenderse desprovisto de connotaciones negativas-. Dichos límites se han ido formulando en relación con tres elementos: la necesidad de la existencia de una «oposición positiva» de puntos de vista entre las partes, el criterio del «conocimiento» de la existencia de la controversia y la relevancia de los intercambios procesales entre las partes.

\subsubsection{La necesidad de una "oposición positiva» de puntos de vista}

28. Fue por primera vez en el dictamen consultivo de 30 de marzo de 1950 sobre la Interpretación de los Tratados de paz concluidos entre Bulgaria, Hungría y Rumanía que la Corte se expresó en estos términos:

"[t]here has [...] arisen a situation in which the two sides hold clearly opposite views concerning the question of the performance or non-performance of certain treaty obligations ${ }^{39}$.

29. Si bien se podría interpretar que se estaba limitando a describir la situación, unos años más tarde la Corte dejó más claro (si cabe) que no era el caso. En efecto, en su sentencia de 1962 sobre el Asunto del Sudoeste Africano, la Corte dejó patente que la «oposición» de puntos de vista era un verdadero criterio jurídico que delimitaba la amplia definición Mavrommatis, indicando que ni puede únicamente confiar en las posturas de las partes respecto de la existencia o inexistencia de la controversia, ni basta con constatar que hay un conflicto de «intereses» entre estas. Por el contrario, a fin de determinar que se ha satisfecho el requisito, se exigió que la reclamación de una parte sea "positivamente opuesta por la otra» (positively opposed by the other) ${ }^{40}$.

30. Esta nueva fórmula permitió distinguir netamente entre «controversias» reales y meras «tensiones internacionales» o «situaciones» (excluyendo estas últimas de la competencia de la Corte $)^{41}$, pero quedó sin explicar. Mientras que la «oposición» de puntos de vista parecía sugerir la necesidad de una contradicción de opiniones, la CIJ no aclaró si es necesario algún tipo de interacción efectiva, bien sea por medio de declaraciones cruzadas o por medio de la crítica a una conducta que la otra parte considera conforme a Derecho.

39 Interpretación de los Tratados de Paz concluidos entre Bulgaria, Hungría y Rumanía, supra, nota 29, p. 74 (redonda añadida).

40 Asunto del Sudoeste Africano (Etiopía c. Sudáfrica y Liberia c. Sudáfrica), objeciones preliminares, supra, nota 10 , p. 328.

41 Remiro Brotóns, A. et al., Derecho Internacional, Valencia, Tirant lo Blanch, 2007, pp. 670-671; Sobrino Heredia, J. M., "Procedimientos de aplicación de las normas internacionales (II)», en DíEz DE Velasco Vallejo, M., Instituciones de Derecho Internacional Público, 18. a ed., Madrid, Tecnos, 2013, pp. 942-943. 
Que ello es el caso, podría inferirse quizá del término "positivo» (aunque este puede ser interpretado de múltiples maneras) o de la interpretación del Juez Morelli en su opinión disidente en el caso $^{42}$. Posteriormente volveremos a esta cuestión.

\subsubsection{El «conocimiento» de la existencia de la controversia}

31. Las recientes sentencias sobre las obligaciones nucleares se han referido a un nuevo (y controvertido) criterio: el "conocimiento» por el demandado de las pretensiones jurídicas opuestas del demandante.

Recordemos que, ante la Corte, las Islas Marshall invocaban una serie de elementos de prueba que, a su entender, demostraban la existencia de una controversia antes incluso de presentarse la demanda. El principal consistía en dos declaraciones formuladas en foros multilaterales ${ }^{43}$. La primera tiene por fecha el 26 de septiembre de 2013 y fue pronunciada por el ministro de Asuntos Exteriores en una Reunión de alto nivel de la Asamblea General sobre el desarme nuclear:

"We argue all nuclear weapons states to intensify efforts to address their responsibilities in moving towards an effective and secure disarmament».

La segunda tiene por fecha el 24 de abril de 2014 y fue formulada por el representante de las Islas Marshall en la Segunda Conferencia sobre el impacto humanitario de las armas nucleares celebrada en Nayarit (México):

"[T]he Marshall Islands is convinced that multilateral negotiations on achieving and sustaining a world free of nuclear weapons are long overdue. Indeed we believe that States possessing nuclear arsenals are failing to fulfil their legal obligations in this regard. Immediate commencement and conclusion of such negotiations is required by legal obligation of nuclear disarmament resting upon each and every State under Article VI of the Non-Proliferation Treaty and customary international law».

32. La Corte rechazó que ambas declaraciones probaran la existencia de una controversia entre las partes, bien por separado o interpretadas conjuntamente ${ }^{44}$. Se valió para ello de la falta de «conocimiento» por los demandados de las pretensiones jurídicas opuestas del demandante. En sus propias palabras:

42 Para quien lo esencial es una «manifestación de voluntad» por una de las partes [Asunto del Sudoeste Africano (Etiopía c. Sudáfrica y Liberia c. Sudáfrica), objeciones preliminares, supra, nota 10, pp. 567-568, párrs. 2-3]. Véase también la Opinión individual del Juez Owada en las sentencias sobre las obligaciones nucleares (supra, nota 2, párr. 7) y KoLB, R., loc. cit., nota 4, p. 100.

43 El segundo elemento fue la propia presentación de la demanda ante la Corte, que para las Islas Marshall era constitutiva de una controversia internacional. Y, por último, el tercer elemento era la conducta de los demandados relativa al desarme nuclear (y en el caso de Pakistán y Reino Unido, relativa a la negociación del desarme nuclear) antes y después de dicho momento.

${ }^{44}$ Obligaciones respecto de las negociaciones sobre la cesación de la carrera de armamentos nucleares y el desarme nuclear (Islas Marshall c. India), supra, nota 2, párr. 48. 
"The evidence must show that the parties "hold clearly opposite views" with respect to the issue brought before the Court [...]. As reflected in previous decisions of the Court in which the existence of a dispute was under consideration, a dispute exists when it is demonstrated, on the basis of the evidence, that the respondent was aware, or could not have been unaware, that its views were "positively opposed" by the applicant» 45 .

33. En otra parte de las sentencias, la CIJ retomó un planteamiento formulado en Georgia c. Rusia, indicando que una declaración solo puede dar lugar a una controversia si se refiere a la materia en cuestión «with sufficient clarity to enable the State against which [that] claim is made to identify that there is, or may be, a dispute with regard to that subject-matter» ${ }^{46}$. En consecuencia, explicó que el tema de la Conferencia de Nayarit no era tanto el desarme nuclear, sino el impacto humanitario de las armas nucleares. Pero, sobre todo, se refirió al contenido de la declaración de Nayarit, que según la Corte no especificaba qué conducta concreta del demandado justificaba las acusaciones formuladas por las Islas Marshall. Este último aspecto fue considerado a la luz de las circunstancias particulares, dado que las tres demandas criticaban un patrón de conducta que había perdurado durante años sin que el demandante hubiera formulado protesta alguna ${ }^{47}$.

\subsubsection{La limitada relevancia de los intercambios procesales entre las partes}

34. El nuevo criterio del "conocimiento" de las pretensiones de la otra parte no hubiera bastado para desestimar las tres demandas si se hubiera aceptado la alegación marshalesa según la cual una demanda equivale a una notificación de la existencia de una controversia. El demandante invocó a este respecto la tradicional laxitud de la Corte en cuanto al cumplimiento de requisitos formales que pueden subsanarse con facilidad (lo que el Juez Crawford denominó el "principio Mavrommatis») ${ }^{48}$, así como la metodología aplicada en ciertas sentencias ${ }^{49}$.

\footnotetext{
45 Ibid., párr. 38 (redonda añadida).

${ }^{46}$ Ibid., párr. 46, en referencia a Aplicación de la Convención Internacional para la Eliminación de Todas las Formas de Discriminación Racial (Georgia c. Rusia), supra, nota 33, párr. 30.

47 Obligaciones respecto de las negociaciones sobre la cesación de la carrera de armamentos nucleares y el desarme nuclear (Islas Marshall c. India), supra, nota 2, párr. 47. En el caso de India, el demandado invocó durante las audiencias orales sus numerosas iniciativas en foros multilaterales a favor de negociar el desarme nuclear; sin embargo, la Corte no dio relevancia al argumento (más detalles en las Opiniones individuales del Vicepresidente Yusuf, párrs. 25-32 y del Juez Bhandari, párrs. 1-50). Y, por último, el Reino Unido esgrimió su ausencia de la conferencia de Nayarit como justificación de su ignorancia de la reclamación de las Islas Marshall. La Corte no consideró decisivos estos argumentos; véase en todo caso CR 2016/3, pp. 19-20, párrs. 23-26 y pp. 26-27, párrs. $42-44$ (Bethlehem) y CR 2016/7, pp. 18-19, párrs. 32-35 (Bethlehem).

48 Conforme al mismo, "[t]he Court, whose jurisdiction is international, is not bound to attach to matters of form the same degree of importance they might possess in municipal law»: véase Asunto de las concesiones Mavrommatis en Palestina (Grecia c. Reino Unido), supra, nota 15, p. 34. La regla fue refinada en Croacia c. Serbia, en el contexto de una demanda presentada cuando el demandado no era
} 
35. La Corte respondió de la siguiente manera:

"In principle, the date for determining the existence of a dispute is the date on which the application is submitted to the Court [...].

Conduct subsequent to the application (or the application itself) may be relevant for various purposes, in particular to confirm the existence of a dispute [...] to clarify its subject-matter [...] or to determine whether the dispute has disappeared as of the time when the Court makes its decision [...].

However, neither the application nor the parties' subsequent conduct and statements made during the judicial proceedings can enable the Court to find that the condition of the existence of a dispute has been fulfilled in the same proceedings [...]. If the Court had jurisdiction with regard to disputes resulting from exchanges in the proceedings before it, a respondent would be deprived of the opportunity to react before the institution of proceedings to the claim against its own conduct. Furthermore, the rule that the dispute must in principle exist prior to the filing of the application would be subverted ${ }^{50}$.

36. Más adelante se discutirán los detalles de este razonamiento, cuestionado por varios jueces que entendían que debería permitirse que una controversia in statu nascendi como la planteada por las Islas Marshall pudiera cristalizar mediante la presentación de una demanda ${ }^{51}$. Por el momento, baste con comprobar que la solución de la Corte trató de evitar la paradoja según la cual, si los requisitos formales deben reunirse «en principio» cuando la demanda es recibida por la Secretaría («principio Mavrommatis»), permitir que la mera comunicación de la demanda cree una controversia tornaría superfluo todo análisis de la cuestión (y con ello la jurisprudencia en la materia) ${ }^{52}$.

\section{3. ¿FORMALISMO SIN CAUSA? CONTROVERSIA INTERNACIONAL Y FUNCIÓN JUDICIAL DE LA CORTE}

37. Una vez identificados los hitos de la jurisprudencia en la materia, se hace necesario responder a los interrogantes planteados en la introducción

\footnotetext{
todavía parte en el Estatuto de la Corte, al señalarse que «the Court, like its predecessor, has also shown realism and flexibility in certain situations in which the conditions governing the Court's jurisdiction were not fully satisfied when proceedings were initiated but were subsequently satisfied, before the Court ruled on its jurisdiction": véase Aplicación de la Convención para la Prevención y la Sanción del Crimen de Genocidio (Croacia c. Serbia), Sentencia de 18 de noviembre de 2008 sobre objeciones preliminares, ICJ Reports 2008, p. 438, párr. 81.

49 Tales como Ciertas propiedades (Liechtenstein c. Alemania), Camerún c. Nigeria y Aplicación de la Convención para la Prevención y la Sanción del Crimen de Genocidio (Bosnia-Herzegovina c. Yugoslavia). Más detalles en infra, nota 91.

${ }^{50}$ Obligaciones respecto de las negociaciones sobre la cesación de la carrera de armamentos nucleares y el desarme nuclear (Islas Marshall c. India), supra, nota 2, párrs. 40-41.

51 Véase, por todos, la Opinión disidente del Juez Crawford: "[t]o put it at its lowest, there was an incipient dispute between the Marshall Islands and the nuclear-weapon States at the time of Nayarit [...] by the time of Nayarit, by stages, tentatively, but in time, the Marshall Islands had associated itself with one side of that multilateral disagreement, revealing sufficiently for present purposes a claim in positive opposite opposition to the conduct and claims of the nuclear-weapons States, including the respondent State» (párr. 25).

52 Argumento compartido por el Juez Crawford (ibid., párr. 24). Véase también Gross, L., Essays on International Law and Organization, Dordrecht, Martinus Nijhoff, 1984, p. 1055.
} 
a este trabajo, relativos al fundamento de la jurisprudencia más reciente de la Corte. Ello se hará mediante la evaluación de los requisitos que fijan el mínimo común denominador de la noción de controversia internacional (a su vez, los más controvertidos): el criterio del conocimiento y la necesidad de que esta surja antes de la demanda. Respecto del primero, se explicará que no es ni tan novedoso, ni tan subjetivo, ni tan formalista como se ha sugerido. En relación con el segundo (pieza clave de las sentencias relativas a las obligaciones nucleares) se intentará explicar su conexión con la protección de la función judicial de la Corte en relación con demandas unilaterales. Para ello, se abordarán los posibles motivos que han llevado a la Corte a rechazar la posibilidad de que una controversia «cristalice» mediante una demanda.

\subsection{El criterio del «conocimiento»: tentativa de justificación}

\subsubsection{No tan novedoso: el conocimiento en la jurisprudencia previa de la Corte}

38. Son numerosas las voces según las cuales el nuevo criterio del «conocimiento» de la existencia de una controversia no encuentra acomodo en la jurisprudencia previa de la Corte ${ }^{53}$. A decir verdad, la sección relativa al Derecho aplicable de las sentencias sobre las obligaciones nucleares sugiere lo que Prospel Weil ha denominado «la ficción del continuum jurisprudencial», o la aparente existencia de una jurisprudencia constante allá donde, en realidad, no la hay ${ }^{54}$. Ello no implica, sin embargo, que el criterio del conocimiento (entre otros elementos de las sentencias) sea una creación de la Corte. Por el contrario, en mi opinión, la Corte desarrolla su jurisprudencia anterior en función de las circunstancias planteadas en el caso concreto. Ello es así no solo porque el «conocimiento» de las pretensiones del demandante haya sido considerado ya en dos sentencias recientes, sino también (y sobre todo) por-

\footnotetext{
53 Así, para el Vicepresidente Yusuf, a la Corte le hubiera bastado con aplicar el test de la «oposición positiva» (Opinión particular, párr. 16). Para el Juez Cançado Trindade, el nuevo criterio «undermin[es the Court's] own ability to infer the existence of a dispute from the conflicting courses of conduct of the contending parties» (Opinión disidente, párr. 19). Según la Jueza Sebutinde, "[t]his new test is not only alien to the established jurisprudence of the Court but also directly contradicts what the Court has stated in the past and with no convincing reasons» (Opinión disidente, párr. 30). Para el Juez Robinson, "[t]he paragraphs relied upon by the Majority as establishing awareness as a criterion of a dispute should be contrasted with the establishment of an "awareness" or "knowledge" test in other decisions of the Court, and the care the Court takes in setting up a test of this nature» (Opinión disidente, párr. 35). El Juez Crawford afirmó que "[w] hile the term "awareness" has sometimes been used in other cases in deciding whether there was a dispute, it has never been stated as a legal requirement, only as a description of the factual situation» (Opinión disidente, párr. 6). Según el Juez ad hoc Bedjaoui la Corte "se couvre aujourd'hui des nuages menaçants de la décision de 2011, pourtant fondée sur une clause compromissoire facultative, de sorte qu'une ambiguïté certain brouille le panorama» (Opinión disidente, párr. 25). Incluso el Presidente Abraham consideró que, antes de la sentencia Georgia c. Rusia, la Corte era menos rigurosa en la definición de la existencia de una controversia, y que la presente sentencia sigue la línea jurisprudencial más reciente (Declaración, párr. 4).

54 WeIL, P., Perspectives du droit de la délimitation maritime, París, Pédone, 1994, p. 15.
} 
que es la premisa lógica de la aceptada caracterización de las controversias internacionales como "oposición positiva» de puntos de vista.

39. En efecto, la necesidad de que el demandado conozca el punto de vista contrario de la otra parte (formalizado en las sentencias de 2016) hunde sus raíces en la sentencia sobre el Sudoeste Africano, que ya recogía el nudo gordiano del criterio ${ }^{55}$. Como indica el Juez Owada en su opinión individual adjunta a las sentencias relativas a las obligaciones nucleares:

"[i]n international relations between States, as is so often the case between individuals, States frequently adopt different or divergent opinions on a given issue. Such differences or divergences, even when they are well established, do not ipso facto represent a legal dispute of which a court of law can be seized for adjudication [...] It is this positive opposition manifested between the parties which transforms a mere factual disagreement into a legal dispute susceptible of adjudication» ${ }^{56}$.

En un contexto multilateral en donde se intercambian a diario puntos de vista jurídicos en foros y conferencias internacionales, no puede haber «oposición positiva» de puntos de vista si la reclamación de una parte no "alcanza» como tal a la otra, quedando así las opiniones divergentes de las partes como barcos que se cruzan de noche ${ }^{57}$.

40. Además, la «oposición positiva» de puntos de vista requiere que la reclamación tenga un nivel mínimo de concreción para que el demandado pueda tener constancia ( «conocimiento») de qué conducta es considerada contraria a Derecho ${ }^{58}$. El nivel de concreción de la reclamación dependerá de las circunstancias. De las sentencias relativas a las obligaciones nucleares parece desprenderse que, en contextos multilaterales, no basta ni con que el demandante forme parte de un grupo de Estados opuestos a la conducta del demandado, ni con el sentido de su voto respecto de resoluciones relevantes en la materia (elemento acogido con escepticismo por la Corte pero que, no está de más afirmar, fue bastante errático en el caso de las Islas Marshall) ${ }^{59}$.

55 Contra, Becker, M., loc. cit., nota 4, pp. 14-15. Este autor se refiere a las circunstancias particulares del caso, obviamente diferentes a las de las planteadas por las Islas Marshall. A mi juicio ello no impide considerar la relevancia de una sentencia que se refería a la noción de controversia de manera general, al margen de la cuestión particular del interés de los demandantes en actuar ante la Corte.

56 Opinión individual del Juez Owada, párr. 6.

57 Michael Becker pregunta a este respecto: de lo contrario, "what is the difference between views that are "positively opposed" and the mere existence of "opposing views"?" (loc. cit., nota 4, p. 14).

58 Como acertadamente explica la Jueza Donoghue en su Opinión individual, el problema planteado en los asuntos relativos a las Islas Marshall no es tanto el conocimiento por parte del demandado de las declaraciones formuladas por el demandante (que la Corte asume), sino si dichas declaraciones se referían con suficiente claridad a la problemática planteada en La Haya (párr. 8). Contra, la Opinión disidente de la Jueza Sebutinde (párr. 26) y PALESTINI, L., loc. cit., nota 4, p. 566.

59 En efecto, después de votar a favor durante años, entre los años 2003 y 2012 las Islas Marshall cambiaron el rumbo, avalando solo una vez (en 2004) la resolución anual de la Asamblea General relativa al Dictamen consultivo sobre la Legalidad de la amenaza o el uso de armas nucleares que reclama a los Estados comenzar las negociaciones sobre desarme nuclear. En el resto de ocasiones (ocho) se abstuvieron, e incluso en el año 2003 votaron en contra (más detalles en la opinión particular del Juez Bhandari, párr. 36). Los demandados tomaron buena nota de dicho patrón de voto para apoyar sus argumentos: véase, en particular, CR 2016/4, p. 18, párr. 11 (Gill). 
41. Otro factor a tener en cuenta es el temporal, sobre todo si la conducta del demandado se produce durante un largo periodo de tiempo sin que el demandante se pronuncie al respecto. Como afirman las tres sentencias, "[s] uch a specification would have been particularly necessary if, as the Marshall Islands contends, the Nayarit statement as aimed at invoking the international responsibility of the Respondent on the grounds of a course of conduct which had remained unchanged for many years $\gg$.

42. Por todo ello, en mi opinión, el conocimiento del punto de vista opuesto del demandante es la premisa lógica de la «oposición manifiesta» de puntos de vista. Al margen de que se compartan o no las conclusiones de la Corte respecto de la declaración de Nayarit, resulta difícil cuestionar la formulación de tal criterio. No es casualidad que, en un posible lapsus al que la Corte no prestó atención, las Islas Marshall utilizaran el término en cuestión precisamente para explicar las consecuencias de sus propias declaraciones sobre los demandados ${ }^{61}$.

43. Pero aún hay más: las sentencias sobre objeciones preliminares dictadas en Georgia c. Rusia y Nicaragua c. Colombia (y, en menor medida, Bélgica c. Senegal) hacían presagiar la relevancia del test del «conocimiento», pues en la primera la Corte se refirió al conocimiento por parte de Rusia de ciertos planteamientos o iniciativas georgianas en su análisis de los intercambios entre las partes ${ }^{62}$; y en la segunda se concluyó que "Colombia was aware that its enactment of Decree 1946 and its conduct in the maritime areas declared by the 2012 Judgment to belong to Nicaragua were positively opposed by Nicaragua» ${ }^{6}$ (aunque la utilización de esta última decisión no está exenta de controversia, porque se dictó al día siguiente de terminar las audiencias orales en los asuntos relativos a las obligaciones nucleares) ${ }^{64}$.

44. Ciertamente, en ambas decisiones el criterio entró por la puerta de atrás de la aplicación del derecho a las particulares del caso, y no por la puerta de entrada de la formulación del derecho aplicable (es lo que llevó a varios jueces a estimar que dicho requisito era una constatación fáctica en lugar de un criterio jurídico) ${ }^{65}$. Pero a mi modo de ver, la distinción no es relevante:

${ }^{60}$ Obligaciones respecto de las negociaciones sobre la cesación de la carrera de armamentos nucleares y el desarme nuclear (Islas Marshall c. India), supra, nota 2, párr. 47.

61 Statement of Observations of the Marshall Islands re Preliminary Objections Raised by the United Kingdom, de 15 de octubre de 2015, párr. 41.

${ }^{62}$ Aplicación de la Convención Internacional para la Eliminación de Todas las Formas de Discriminación Racial (Georgia c. Rusia), supra, nota 33, p. 63, párr. 100 y p. 120, párr. 113.

63 Asunto sobre las supuestas violaciones de derechos soberanos y espacios marítimos (Nicaragua c. Colombia), supra, nota 3, pp. 32-33, párr. 73. Contra, Palestini, L., loc. cit., nota 4, párr. 565 (por razones que no me parecen convincentes). Respecto a Bélgica c. Senegal, la Corte no argumentó en términos de "conocimiento"su desestimación de las pretensiones de Bélgica respecto de ciertas obligaciones consuetudinarias relacionadas con la prohibición de la tortura. Aun así, a mi entender, dicha sentencia tiene cierta relevancia. Como afirmó el entonces Juez Abraham en su Opinión individual, «le différend relatif au droit conventionnel s'était manifesté, par les échanges entre les Parties, avant même l'introduction de la requête, tandis que le différend relatif au droit coutumier ne s'est manifesté que par leurs échanges devant la Cour» (supra, nota 3, párr. 12, redonda añadida).

64 Prouxl, V.-J., loc. cit., nota 4, p. 12.

65 Véase, por todas, la Opinión disidente del Juez Crawford, párr. 6. 
que un criterio se formule de uno u otro modo, lo importante es su aplicación a la resolución del caso; eso es algo que la Corte hizo en ambas sentencias ${ }^{66}$.

45. Se ha argumentado también que la sentencia Georgia c. Rusia versaba sobre una cláusula jurisdiccional cuyas condiciones no son aplicables a una cláusula facultativa ${ }^{67}$. Aunque relevante, no me parece un argumento definitivo. Que una condición se refiera a una cláusula jurisdiccional que limita la competencia de la Corte a cierto tipo de controversias no implica su exclusión automática de otros supuestos cuando hay ratio legis ${ }^{68}$. Desde esta perspectiva, resulta justificado aplicar a las cláusulas facultativas del art. 36.2 del Estatuto el requisito (planteado en Georgia c. Rusia respecto de una cláusula jurisdiccional) según el cual los intercambios entre las partes deben ser lo suficientemente claros como para que el demandado pueda deducir de ellos las pretensiones de la otra parte ${ }^{69}$.

\subsubsection{No tan subjetivo: conocimiento y «estado mental» del Estado}

46. Otro de los planteamientos esgrimidos contra el test del «conocimiento» se refiere a su subjetividad, en el sentido de que dicho criterio requiere indagar (en palabras de una jueza disidente), "into the "mind" of a respondent State in order to find out about its state of awareness ${ }^{70}$.

47. Antes de analizarse el argumento, es necesaria una aclaración. Las sentencias relativas a las obligaciones nucleares no establecen, a mi modo de ver, un criterio que requiera ser considerado de manera constante por la Corte $^{71}$. Por el contrario, en la práctica, esta solo deberá valorar la existencia de «conocimiento» cuando así lo requieran las circunstancias — por ejemplo, porque el demandado cuestiona la existencia de una controversia ante la falta de interacción previa entre las partes-; así parecen confirmarlo recientes autos sobre medidas provisionales ${ }^{72}$.

66 Véase también la Sentencia arbitral de 18 de marzo de 2015 en el Asunto de la República de Mauricio c. Reino Unido, no publicada todavía, párr. 382 (disponible en https://www.pcacases.com/web/ view/11, 20 de noviembre de 2017): "[i]n the Tribunal's view, Article 283 [of UNCLOS] requires that a dispute have arisen with sufficient clarity that the Parties were aware of the issues in respect of which they disagreed".

67 Véase, en particular, la Opinión disidente del Juez Bennouna (sin párrafos).

${ }_{68}$ Ya lo hizo la CPJI en Compañía de Electricidad de Sofía y Bulgaria (Bélgica c. Bulgaria), supra, nota 3, p. 83, en relación con el elemento temporal que será analizado infra.

69 En el mismo sentido: véase SERENI, A. P., Diritto internazionale IV. Conflitti internazionali, Milán, Giuffrè, 1965, pp. 1589-1590. Mutatis mutandis, véase también KDHIR, M., Dictionnaire juridique de la Cour internationale de Justice, 2. ${ }^{\text {a }}$ ed., Bruselas, Bruylant, 2000, p. 129.

${ }^{70}$ Opinión disidente de la Jueza Sebutinde, párr. 31.

71 Contra, Becker, M., loc. cit., nota 4, p. 14.

72 Asunto Jadhav (India c. Pakistán), Auto de 18 de mayo de 2017 (no publicado todavía), párr. 29; Aplicación de la Convención Internacional para la Supresión de la Financiación del Terrorismo y de la Convención Internacional para la Eliminación de Todas las Formas de Discriminación Racial (Ucrania c. Rusia), Auto de 19 de abril de 2017 (no publicado todavía), párrs. 22-23 e Inmunidades y procedimientos penales (Guinea Ecuatorial c. Francia), Auto de 7 de diciembre de 2016 (no publicado todavía), párrs. 47 y 66. 
48. Ya en relación con el supuesto carácter «subjetivo» del test del conocimiento, debe anotarse en primer lugar el doble componente del criterio. Bajo la fórmula abreviada de "conocimiento» se esconde en realidad un doble test escalonado. El primero, y más exigente, es el del conocimiento en sentido estricto por parte del demandado de las pretensiones contrarias del demandante. Si este no se cumple, todavía es posible satisfacer el segundo test de la "imposibilidad de que el demandado pudiera desconocer» ("could not have been unaware, ne pouvait ne pas avoir connaissance») las pretensiones del demandante. Este último test es puramente objetivo.

49. Respecto de la primera parte del test, es indudable que la valoración del nivel de conocimiento por parte de un Estado de una pretensión jurídica «opuesta» ofrece un amplio margen de apreciación judicial, como se ha podido apreciar en las sentencias relativas a las obligaciones nucleares ${ }^{73}$. Pero ello no excluye el carácter objetivo de la determinación por parte de la Corte del conocimiento de la existencia de una controversia, pues, como apunta uno de los jueces disidentes, "it is [...] perfectly posible to conduct an objetive examination of a subjective factor ${ }^{74}$. En efecto, la Corte no necesita apreciar el estado de «consciencia» del Estado respecto de una situación (como quizá pudiera deducirse de una traducción errónea del término inglés awareness $)^{75}$, sino que efectuará una evaluación objetiva del mensaje comunicado a la luz de las circunstancias de hecho, tal y como hizo la Corte en las sentencias $\mathrm{Ni}$ caragua c. Colombia y obligaciones nucleares.

50. La determinación del «conocimiento» del Estado de un determinado hecho o situación no es ajena al Derecho internacional. Los artículos de la CDI sobre la responsabilidad internacional del Estado incorporan el «conocimiento" (awareness) como criterio jurídico en los arts. 16.a) y 18 en relación con la responsabilidad por ayuda, asistencia y coerción, respectivamente ${ }^{76}$. El Tribunal de Justicia de la Unión Europea se ha referido a la «imposibilidad de ignorar» a efectos de determinar la responsabilidad del Estado ex art. 4 de la Carta de Derechos Fundamentales por el traslado de un solicitante de asilo a otro Estado miembro donde corre el riesgo de ser sometido a tratos inhumanos y degradantes ${ }^{77}$. Asimismo, la «imposibilidad de desconocer» fue

73 La Corte dispone de un margen similar para determinar la materia de la controversia, una cuestión que, como es sabido, puede ser decisiva para su competencia: véanse Obligación de negociar un acceso al Océano Pacífico (Bolivia c. Chile), supra, nota 30, p. 609, párr. 50, y Competencia en materia de pesquerías (España c. Canadá), Sentencia de 4 de diciembre de 1998, ICJ Reports 1998, p. 467, párr. 87.

74 Opinión disidente del Juez Robinson, párr. 25.

${ }^{75}$ Aunque no es la auténtica, la versión francesa de las sentencias aclara el término de la versión inglesa.

76 Según el cual la responsabilidad internacional por ayuda o asistencia solo puede producirse cuando el Estado "[l]o hace conociendo las circunstancias del hecho internacionalmente ilícito» [artículos sobre responsabilidad del Estado por hechos internacionalmente ilícitos, Anuario de la CDI, 2001, vol. II, Parte II, A/CN.4/SER.A/2001/Add.1 (Part 2)]. En relación con dicho test, véase GARRIDO Muñoz, A., Garantías judiciales y sanciones antiterroristas del Consejo de Seguridad de Naciones Unidas. De la técnica jurídica a los valores, Valencia, Tirant lo Blanch, 2013, pp. 263-270 y las referencias allí citadas.

77 Asunto C-411/10, ECLI:EU:C:2011:865, párr. 94. 
decisiva en el Asunto sobre el estrecho de Corfú en relación con la responsabilidad de Albania por la colocación de minas que afectaron a dos buques de guerra británicos y su tripulación ${ }^{78}$.

\subsubsection{No tan formalista: la prueba del conocimiento}

51. Como ya se ha indicado, es en la crítica al formalismo de la Corte donde más convergen las opiniones de jueces disidentes y comentaristas. En general, se considera que el criterio del conocimiento equivale de hecho a requerir una notificación al Estado demandado, lo que contradice la jurisprudencia según la cual ni la notificación de la intención de iniciar un procedimiento judicial ni la protesta diplomática formal son necesarias para la existencia de una controversia ${ }^{79}$.

52. Además, se cuestiona la evaluación por la Corte del factor temporal, que fue decisivo de las citadas sentencias. En este sentido, se discrepa de la necesidad de que la controversia cristalice antes de la demanda para que el requisito se cumpla. Dicho argumento se fundamenta en dos motivos: por un lado, que la jurisprudencia de la Corte solo indica que la controversia debe «en principio» existir en el momento de la demanda ${ }^{80}$; por otro, que la Corte ha sido siempre flexible en relación con el cumplimiento de requisitos formales que pueden satisfacerse una vez iniciado un procedimiento ("principio Mavrommatis») ${ }^{81}$; tanto más cuanto que, en el caso de las Islas Marshall, la presentación de la demanda subsanó el defecto formal ${ }^{82}$.

53. A mi juicio, requerir que se conozca o no se pueda ignorar una controversia no equivale de hecho a requerir una notificación. Obviamente, comunicar por la vía diplomática el desacuerdo con otro Estado resolverá, o al menos facilitará la labor (aún más si cabe cuando las partes intentan lograr una solución negociada antes de someter la controversia al arreglo judicial) ${ }^{83}$. Pero ello no implica que la jurisprudencia más reciente haya renunciado a la regla según la cual no es necesario un intercambio formal entre las partes, pues todo dependerá de las circunstancias. Así lo confirma la sentencia

78 Asunto sobre el estrecho de Corfú (Reino Unido c. Albania), Sentencia de 9 de abril de 1949, ICJ Reports 1949, pp. 22-23. También Asunto anglo noruego de pesquerías (Reino Unido c. Noruega), Sentencia de 18 de diciembre de 1951, ICJ Reports 1951, p. 139.

79 BECKer, M., loc. cit., nota 4, p. 10.

80 Como se explica en detalle en la Opinión individual del Juez Tomka (párr. 15).

${ }^{81}$ Asunto de las concesiones Mavrommatis en Palestina (Grecia c. Reino Unido), supra, nota 14, p. 34, y Aplicación de la Convención para la Prevención y la Sanción del Crimen de Genocidio (Croacia c. Serbia), supra, nota 48, p. 438, párr. 81 y p. 441, párr. 85 .

82 En este sentido, las sentencias no son fáciles de explicar desde un punto de vista de la economía judicial, pues el demandante habría podido plantear una nueva demanda ante la Corte. Indudablemente, las sentencias se habrían beneficiado de un análisis de las objeciones preliminares formuladas por los demandados, como sugieren los Jueces Gaja y Bhandari.

83 Véase, entre otros muchos, Wellens, K., Economic Conflicts and Disputes Before the Word Court (1922-1995). A Functional Analysis, La Haya/Boston/Londres, Kluwer Law International, 1996, p. 16. 
de 2016 en Nicaragua c. Colombia, en la que, recordemos, por un lado la ausencia de notificación previa no impidió la existencia de una controversia relativa a los derechos soberanos del demandante en ciertas zonas del Mar del Caribe; y, por otro, se consideró que no existía una controversia relativa a las supuestas violaciones colombianas de la prohibición de la amenaza o uso de la fuerza.

54. En consecuencia, la aproximación poco formalista del Juez Morelli, integrada por la Corte en la citada Camerún c. Nigeria, sigue a mi juicio siendo aplicable:

"the dispute may result from a claim by one of the parties followed either by the denial of that claim by the other party or by a course of conduct by the other party contrary to the claim. But there may also be a dispute resulting first of all from a course of conduct by one of the parties against which the other party raises a protest» ${ }^{84}$.

Esta tesis se aplica en particular a las controversias bilaterales de larga data, en las cuales es incluso factible asumir que una determinada conducta no objetada expresamente no pueda ser ignorada como susceptible de oposición jurídica por la otra parte — eventualidad cada vez menos probable en la era Twitter-. Una conclusión similar parece aplicable a una controversia que pueda concernir a un grupo reducido de Estados.

55. En cuanto a las controversias multilaterales ${ }^{85}$, después de las sentencias relativas a las obligaciones nucleares, parece razonable inferir que se requerirá algo más del demandante a efectos de considerar satisfecho el requisito de existencia de una demanda, pues este no podrá ampararse únicamente en patrones de voto en la AGNU ni en la conducta del demandado, al menos cuando estemos ante una conducta continuada por parte del demandado que no fue objeto de protesta. Se trata de un efecto colateral de la no exigencia de perjuicio material individualizable como requisito de admisibilidad de una demanda relativa a una obligación erga omnes ${ }^{86}$; criterio afortunadamente abandonado por la Corte, pero cuya ausencia requiere que se señale el desacuerdo con mayor claridad a la otra parte.

56. En síntesis, en las sentencias relativas a las obligaciones nucleares, la Corte ha buscado bilateralizar un contexto multilateral, encauzando de esta manera su (indiscutible) competencia para resolver controversias multilate-

${ }^{84}$ Opinión disidente en el Asunto del Sudoeste Africano (Etiopía c. Sudáfrica y Liberia c. Sudáfrica), objeciones preliminares, supra, nota 10, párr. 4. No está de más citar la opinión disidente del Juez ad hoc Caron en Nicaragua c. Colombia, quien discrepó abiertamente de la aproximación anti-formalista de la Corte a las circunstancias del caso (pp. 19-23, párrs. 80-82).

85 Por controversia multilateral, me refiero a aquella que interesa a la comunidad internacional en su conjunto y cuya resolución puede depender de una acción conjunta de un grupo de Estados o de una organización internacional. Sobre los tratados que regulan este tipo de materias, véase RoDRIGo HERNÁNDEZ, A. J. y ABEGón, M., «El concepto y efectos de los tratados de protección de intereses generales de la comunidad internacional», REDI, vol. 69, 2017, núm. 1, pp. 167-193. Sobre las controversias cuya resolución depende de una acción conjunta de varios Estados, véase supra, nota 8.

${ }^{86}$ Como se recuerda en la Opinión disidente del Juez Crawford (párrs. 20-21). 
rales $^{87}$. Dicha «bilateralización» se tendrá que producir con un nivel mínimo de concreción, de manera que el demandado conozca o no pueda ignorar qué conducta se le imputa y qué obligaciones jurídicas se invocan en su contra; la forma no es decisiva, sino que es un elemento más a tener en cuenta ${ }^{88}$.

\subsection{El elemento temporal de la controversia internacional y la función judicial de la Corte: tentativa de explicación}

57. En las sentencias relativas a las obligaciones nucleares, la Corte ha justificado la fijación de límites temporales al requisito de la existencia de la controversia en torno a un argumento de justicia procesal. Recordémoslo:

"[i]f the Court had jurisdiction with regard to disputes resulting from exchanges in the proceedings before it, a respondent would be deprived of the opportunity to react before the institution of proceedings to the claim against its own conduct. Furthermore, the rule that the dispute must in principle exist prior to the filing of the application would be subverted» ${ }^{89}$.

58. Este fragmento ha sido cuestionado desde dos puntos de vista.

Por un lado, en conexión con el citado «principio Mavrommatis», se ha argumentado que contradice una serie de sentencias anteriores en las que se justificó la existencia de una controversia en base a los intercambios procesales mantenidos por las partes ${ }^{90}$. Aunque relevante, el argumento no nos parece concluyente, pues ni la jurisprudencia previa es clara ${ }^{91}$, ni el «principio Mavrommatis» debe aplicarse a una condición formal que protege al demandado antes de incoarse un procedimiento (como tampoco debe aplicarse, por ejemplo, a una cláusula jurisdiccional que requiera intentar negociar, por el simple hecho de que los intercambios entre las partes ante la Corte eviden-

87 ProuxL, V.-J., loc. cit., nota 4, p. 8.

88 Contra, Becker, M., loc. cit., nota 4, p. 10, y Galindo, G. R. B., loc. cit., nota 4, p. 76.

89 Supra, nota 2, párr. 40.

90 Véase por todas la Opinión disidente del Juez Bennouna (sin párrafos). Otra opinión autorizada en este sentido puede encontrarse en SHAw, M. N., Rosenne's Law and Practice of the International Court: 1920-2015, Leiden/Boston, Brill, 2016, pp. 510-511.

91 En efecto, a mi entender, ninguno de los tres precedentes citados como contrarios a las tres sentencias de 2016 es totalmente concluyente. El primero es el Asunto de Timor Oriental (Portugal c. Australia). Si bien la Corte resolvió la cuestión de la existencia de una controversia sobre la base de los intercambios procesales (pp. 99-100, párr. 22), hubo protesta formal previa por parte de Portugal, como la Corte indica en la propia sentencia (30 de junio de 1995, ICJ Reports 1995, p. 104, párr. 32). El segundo es Bosnia c. Serbia, asunto en el que no hubo intercambios previos, pero que fue decidido en un contexto de hostilidades entre las partes (Aplicación de la Convención sobre la Prevención y la Sanción del Crimen de Genocidio, Sentencia de 11 de julio de 1996 sobre objeciones preliminares, ICJ Reports 1996, pp. 614-615, párrs. 28-29). El tercero es Ciertas Propiedades (Liechtenstein c. Alemania), en el cual hubo negociaciones previas (ICJ Reports 2005, p. 19, párr. 25). Un cierto apoyo (limitado) hacia la tesis contraria puede encontrarse en el Asunto sobre el derecho de paso sobre territorio indio (Portugal c. India), Sentencia de 12 de abril de 1960, ICJ Recueil 1960, pp. 28-29, donde la Corte se basó en la fecha en que la controversia emergió por primera vez a la hora determinar el contenido de su función judicial, y no tanto en la fecha en que dictó su sentencia, cuando el contenido de la controversia había ya evolucionado. 
cien que dicha vía sería infructuosa) ${ }^{92}$. Ello es el caso, al menos, cuando la subsanación del defecto formal se produce mediante la mera presentación de la demanda (a diferencia de otro factor externo, como la entrada en vigor de un tratado o la accesión del demandado a las Naciones Unidas), pues de lo contrario se priva al criterio de cualquier aplicabilidad práctica.

Por otro lado, se ha cuestionado que la figura del requerimiento previo sea aplicable a las relaciones interestatales. Pero ante la poca claridad del Estatuto $^{93}$, la opinión de Georges Abi-Saab (muy citado por las partes durante las audiencias orales en los asuntos planteados por las Islas Marshall) resulta persuasiva. Según este autor:

"[i]l parait difficile d'admettre que l'on puisse assigner un justiciable devant un tribunal sans lui avoir fait connaitre au préalable ce qu'on lui demande et sans lui avoir donné ainsi la possibilité d'y accéder ${ }^{94}$.

59. La necesidad de que la controversia cristalice antes de la demanda también había sido defendida por el Juez Morelli, quien se refirió a este respecto a la sentencia de la CPJI en el Asunto sobre la Compañía de Electricidad de Sofía y Bulgaria (quizá por motivos relacionados con la protección de la función judicial de la Corte) ${ }^{95}$. Mucho antes, el Juez Moore había indicado en su opinión disidente en el Asunto de las concesiones Mavrommatis en Palestina que la necesidad de mantener intercambios mínimos entre las partes es "tested by the ordinary conceptions of fair dealing as between man and man» ${ }^{96}$. Y, más recientemente, el actual secretario de la Corte ha indicado que "[i] nevitably, some form of protest or discussion must predate the submission of

92 Contra, Palestini, L., loc. cit., nota 4, pp. 572-573. Por otro lado, este autor considera que la sentencia Nicaragua c. Colombia no es un precedente relevante, porque en este asunto el Pacto de Bogotá expiró el día después de presentada la demanda, por lo que la Corte se vio forzada a situarse en el momento de presentación de esta (p. 573). Sin embargo, el argumento no es válido, porque la sentencia exigió la existencia de controversia antes de presentarse la demanda, en lugar de aceptar la presentación de la demanda como tal a efectos de establecer la existencia de la controversia.

93 Las sentencias sobre las obligaciones nucleares se apoyan en el art. 38 del Estatuto, que se refiere a las «controversias que le sean sometidas» (supra, nota 2, para. 38). Un cierto apoyo podría encontrarse también en el art. 40.1, que requiere que la demanda indique «el objeto de la controversia y las partes». La ambigüedad del Estatuto ha llevado a Michael Becker a afirmar que el requerimiento de que la controversia exista antes de la demanda es un criterio "político» (loc. cit., nota 4, p. 14, nota al pie 69). Y ello es cierto, pues estamos ante una opción de política judicial que responde a la poca claridad del Estatuto al respecto. Como no es menos cierto que la solución contraria también habría sido una opción de política judicial igualmente legítima.

94 ABI-SAAB, G., Les exceptions préliminaires dans la jurisprudence de la Cour internationale de Justice, París, Pédone, 1967, p. 124.

95 Opinión disidente, supra, nota 84, párr. 4, p. 566 (con referencia a PCIJ, Series A/B, núm. 77, p. 83). Véase también la Opinión disidente de la Jueza Donoghue en Georgia c. Rusia (supra, nota 33, p. 331, nota al pie 2). En el mismo sentido: véanse Bos, M., Les conditions du procès en droit international public, Leiden, Brill, 1957, pp. 200 y 204, y Bourouin, M., «Dans quelle mesure le recours à des négociations diplomatiques est-il nécessaire avant qu'un différend puisse être soumis à la juridiction internationale?», en VVAA, Hommage d'une génération de juristes au Président Basdevant, París, Pédone, 1960, p. 49. Para una interpretación diferente, véase la Opinión disidente del Juez Crawford en las sentencias sobre las Obligaciones de negociar el desarme nuclear, supra nota 2, párr. 14. Véase también Palestini, L., loc. cit., nota 4, p. 570.

96 Asunto de las concesiones Mavrommatis en Palestina (Grecia c. Reino Unido), supra, nota 15, Opinión disidente, p. 61. 
the "dispute" to the Court» ${ }^{97}$. La Corte parece aplicar esta tesis a las demandas de las Islas Marshall, pero lo hace de manera no formalista, en el sentido de no requerir una comunicación formal para poner en conocimiento de la otra parte el contenido de la controversia. Además, deja abierta la posibilidad de que la demanda pueda crear la controversia, pues sigue afirmando que la regla relativa a la existencia de una controversia previa a la demanda se aplica "en principio» ${ }^{98}$.

60. Ahora bien, cabe preguntarse si la protección del demandado basta como explicación del razonamiento de la Corte. Dado que, en su origen, la existencia de una controversia internacional es un requisito que afecta al núcleo de la función judicial de la Corte ${ }^{99}$, resulta necesario indagar si existe alguna conexión entre esta y el tenor de las últimas decisiones en la materia. $\mathrm{Al}$ respecto, las sentencias relativas a las obligaciones nucleares podrían aportar una pista.

61. En efecto, a nadie se le escapa que, tras años de costosa litigación, la función de la Corte de «resolver» controversias entre Estados en las materias indicadas en el art. 38.1 del Estatuto no necesariamente contribuye a mejorar la relación entre las partes. Ello es sobre todo el caso cuando un Estado demanda a otro de manera unilateral, como indicara la CPJI en su sentencia sobre la Interpretación de las sentencias núms. 7 y 8 (Fábrica de Chorzów) de $1927^{100}$.

62. La aplicación de los requisitos de la existencia de una controversia antes de la demanda parece ir encaminada a reforzar una opción de política judicial, como es la de evitar «ataques sorpresa» ante la Corte. Dicha opción podría parecer entroncar con una determinada concepción de la relación entre su función judicial y otros medios de arreglo pacífico de controversias internacionales, en la cual la Corte aparece como opción de última instancia ${ }^{101}$. Sin embargo, a mi juicio, el fundamento último de esta solución radica más

97 Couvreur, Ph., op. cit., nota 21, p. 106. También Thirlway, H., The International Court of Justice, Nueva York, Oxford University Press, 2016, p. 53.

98 A este respecto, no ha clarificado cuáles son las posibles excepciones. El Reino Unido sugirió una en las audiencias orales: la de la situación de urgencia en la cual el demandante no puede esperar a poner en conocimiento de la otra parte la reclamación, tesis cuya aceptación plantearía interesantes interrogantes sobre la relación entre dicha excepción y el criterio de la urgencia requerido para otorgar medidas cautelares: véase CR 2016/3, p. 28, párr. 47 (Bethlehem). También cabría discutir si el demandante no puede igualmente justificar un «ataque sorpresa» en el temor a la retirada o modificación de la base de competencia de la Corte (como ha hecho el Reino Unido en relación con las controversias nucleares). Se trata de una eventualidad invocada por el Juez Tomka para criticar las sentencias relativas a las Obligaciones de negociar el desarme nuclear que, a mi juicio, debería ser considerada con prudencia (párr. 29).

$99 \mathrm{Al}$ respecto, se han criticado las sentencias relativas a las Obligaciones de negociar el desarme nuclear bajo el argumento de que la existencia de una controversia solo busca proteger la función judicial de la Corte: véase BECKER, M., loc. cit., nota 4, pp. 13-14. A mi entender, nada impide que el criterio proteja otros objetivos.

100 Supra nota 22.

101 KolB, R., loc. cit., nota 4, p. 100. Es la doctrina clásica del «sucedáneo»; al respecto, véase por ejemplo MiaJa DE la Muela, A., "Solución de diferencias internacionales (teoría jurídica general)», en Cursos y Conferencias de la Escuela de Funcionarios Internacionales (1955-1956), pp. 211-212. 
bien en una aproximación escéptica a la capacidad de la CIJ de contribuir al arreglo pacífico de controversias (y en sentido más amplio, a las relaciones amistosas entre los Estados) cuando el demandado se enfrenta a un pleito inesperado (casos relativos a las Obligaciones nucleares) o a una pretensión jurídica no planteada previamente en el contexto de una controversia con el demandante (Bélgica c. Senegal y Nicaragua c. Colombia). En tales circunstancias, la Corte debe proteger no solo la situación del demandado ${ }^{102}$, sino también su propia función judicial y, de manera incidental, la cláusula facultativa a fin de evitar retiradas «retributivas» ${ }^{103}$. En todo caso, no se trata de una opción perfectamente coherente, porque la propia Corte había determinado en una jurisprudencia anterior que los «ataques sorpresa» son todavía posibles, en particular cuando el demandante comunica la aceptación de la cláusula facultativa a la Secretaría General de las Naciones Unidas e introduce una demanda en las horas siguientes ${ }^{104}$.

63. Llevando el argumento más lejos, un autor ha sostenido que la noción de controversia se convertirá en un elemento maleable que le permitirá a la Corte aplicar un "certiorari implícito» a fin de evitar asuntos que puedan dificultar su función judicial al no ser «manejables en un procedimiento judicial contradictorio» (en el caso de las demandas marshalesas, porque planteaban cuestiones multilaterales de difícil resolución por la vía bilateral) ${ }^{105}$. Para este autor se trata, en fin, de abordar vía competencia una cuestión que la Corte ha resuelto en otras ocasiones en sede de admisibilidad general ${ }^{106}$. Sin embargo, dejando al margen las demandas planteadas por las Islas Marshall, no parece que los otros dos casos en que el criterio de la existencia de una controversia produjo efectos relevantes se plantearan dificultades particulares a la función judicial de la $\mathrm{CIJ}{ }^{107}$. Por tanto, la relevancia de dicha explicación también está por comprobar.

102 Es dudoso que dicha opción encuentre un fundamento en la Carta de la ONU, pues el Capítulo VI no prevé un método de gradación de los mecanismos de arreglo pacífico de controversias enumerados en el art. 33 de la Carta [véase también la Resolución 2625 (XXV) AGNU]. Ahora bien, tampoco hay contradicción con esta porque la Corte no requiere al demandante entablar negociaciones previas, sino solo que tal posibilidad exista en teoría.

103 Declaración de la Jueza Xue, párrs. 5-6. Véase, igualmente, sobre la cautela, que la Corte debe mostrar ante las «sorpresas» inesperadas por los Estados que aceptan la competencia de la Corte, la Declaración del Juez ad hoc Verhoeven en Actividades Armadas en el territorio del Congo (RDC c. Uganda), Auto de 29 de noviembre de 2001, ICJ Reports 2005, pp. 684-685, relativo a la admisibilidad de una demanda reconvencional.

104 Asunto sobre el derecho de paso sobre territorio indio (Portugal c. India), Sentencia de 26 de noviembre de 1957 sobre excepciones preliminares, ICJ Recueil 1957, pp. 145-147.

105 Kolb, R., loc. cit., nota 4, p. 97. La expresión es de Jennings, R., «Reflections on the Term "Dispute" ", en MacDonald, R. St. J. (ed.), Essays in Honour of Wang Tieya, Dordrecht/Londres/Boston, Martinus Nijhoff, 1993, p. 405. Véase también BiancHI, A., loc. cit., nota 5, p. 82. Hace años una opinión similar fue expresada en Gross, L., op. cit., nota 52, p. 828.

106 Véase, entre otras, la Sentencia en el Asunto del Camerún del Norte (Camerún c. Reino Unido), Sentencia de 2 de diciembre de 1963 sobre objeciones preliminares, ICJ Reports 1963, p. 38.

107 Incluso en Georgia c. Rusia, otro asunto de gran relevancia política, el análisis de la Corte relativo al momento de nacimiento de la controversia entre las partes no condujo a ningún resultado concreto (Opinión individual del Juez Abraham, supra, nota 33, p. 230, párrs. 21-22). 


\section{CONCLUSIONES}

64. ¿Síntoma de creciente formalismo o toma en serio de un requisito que entronca con el núcleo de su función judicial? Con la mira puesta en la jurisprudencia de la CIJ y su predecesora, este trabajo ha mantenido que existen importantes argumentos que fundamentan la segunda opción. Cierto es que se ha constatado la existencia de elementos que muestran al mismo tiempo flexibilidad y rigor respecto del requisito de la controversia internacional. Aun más, se ha apuntado a que ambas tendencias son en cierto modo contradictorias, pues la Corte utilizaba metodologías en tiempos anteriores que han sido desechadas con rotundidad en sentencias más recientes. Pero ello no impide concluir que, particularmente en las sentencias relativas a las obligaciones nucleares, la Corte ha aclarado planteamientos que hasta el momento parecían indeterminados, estableciendo así un mínimo común denominador basado en la existencia de una «oposición positiva de puntos de vista» antes de la demanda como pieza clave del sistema. El criticado criterio del «conocimiento» es parte de dicho mínimo, si bien no parece que vaya a ser aplicado de manera sistemática.

65. Además, este trabajo ha intentado explicar el fundamento de los desarrollos más recientes de la Corte en base a una aproximación «escéptica» a la capacidad de la Corte de cumplir su misión principal de «resolver controversias internacionales» cuando se plantean demandas unilaterales en base a la cláusula facultativa —es decir, cuando el demandado es privado de su teórico derecho a retractarse de su conducta antes de instarse la vía judicial- . No se han descartado otras explicaciones, en particular la que apunta a un uso de la controversia internacional como «certiorari implícito»; si bien la aplicabilidad de esta tesis es limitada, pues en el fondo estamos todavía ante un criterio flexible y fácil de cumplir si los abogados del demandante valoran con cautela la fase pre-procesal. Pero el hecho de que un criterio sea fácil de cumplir no menoscaba en absoluto su relevancia.

66. En fin, se comparta o no, del razonamiento anterior se deduce que hay una lógica jurídica sostenible detrás del aparente rigorismo de la Corte. A nadie sorprende que, al ampararse en criterios formales que pueden ser satisfechos luego de presentada la demanda, la Corte no haya suscitado entusiastas adhesiones académicas. Pero, al menos, la lógica explicada en el presente trabajo refuta argumentos basados en intrigas palaciegas de escaso valor científico, emplazando el debate en lugares doctrinales más reconocibles ${ }^{108}$.

108 Para una acertada crítica a dichas aproximaciones, véase BECKER, M., loc. cit., nota 4, pp. 20-24. 


\title{
RESUMEN
}

\author{
LOS REQUISITOS PROCESALES EN SERIO: LA EXISTENCIA \\ DE UNA «CONTROVERSIA INTERNACIONAL» EN LA JURISPRUDENCIA \\ DE LA CORTE INTERNACIONAL DE JUSTICIA
}

La noción de "controversia internacional» ha cobrado una importancia creciente en la determinación de la competencia de la CIJ. Pero ha sido en las sentencias sobre las Obligaciones relativas a las negociaciones sobre el cese de la carrera de armas nucleares y el desarme nuclear (Islas Marshall c. India, Pakistán y Reino Unido) donde el término ha tenido consecuencias más decisivas. Al hilo de las críticas de "formalismo» vertidas sobre esta jurisprudencia, este trabajo pretende en primer lugar poner la noción en perspectiva histórica, identificando para ello dos tendencias opuestas en la jurisprudencia de la CIJ y su predecesora: una que prioriza la flexibilidad y otra que prioriza el rigor. Seguidamente, se intentará explicar la orientación de las últimas decisiones en la materia desde la óptica de la protección de la función judicial de la Corte.

Palabras clave: Corte Internacional de Justicia, controversia internacional, formalismo, «conocimiento» de la existencia de una controversia, función judicial.

\section{ABSTRACT \\ TAKING PROCEDURAL REQUIREMENTS SERIOUSLY: THE EXISTENCE OF AN «INTERNATIONAL DISPUTE» IN THE CASE LAW OF THE INTERNATIONAL COURT OF JUSTICE}

The notion of «international dispute» has become increasingly relevant in the determination of the ICJ's jurisdiction, but it has been in the judgments rendered in the cases Obligations Concerning Negotiations Relating to Cessation of the Nuclear Arms Race and to Nuclear Disarmament (Marshall Islands v. India, Pakistan and United Kingdom) that the term has been most decisive. Following the allegations of «formalism» made against these decisions, this work aims first to put the notion into historical perspective by identifying two opposing tendencies in the Court's case law: one prioritising flexibility and another one prioritising rigorousness. Next, this work will try to explain the rationale of the most recent decisions on the matter through the prism of the protection of the judicial function of the Court.

Keywords: International Court of Justice, international dispute, formalism, «awareness» of the existence of a dispute, judicial function. 